УДК 378

\title{
ТЕХНОЛОГИЯ ВИРТУАЛЬНОЙ РЕАЛЬНОСТИ В ОБУЧЕНИИ ЛАНДШАФТНОМУ ДИЗАЙНУ
}

\author{
Ли Мэнсинь \\ Аветисян Джавад Давидович \\ к.т.н. профессор \\ Катханова Юлия Федоровна \\ д.п.н., профессор
}

ФГБОУ ВО «Московский педагогический государственный университет»

Аннотация: Авторы статьи показывают возможности технологии виртуальной реальности, которая перенесла обучение, бизнес и другие виды деятельности человека в трехмерное пространство. Виртуальная реальность это технология, которая на сегодняшний день начала использоваться в процессе подготовки специалистов ландшафтного дизайна, предоставляя опыт изучения ландшафтных объектов путем сравнения различных планов между собой, определения наиболее приемлемых вариантов для реализации проектов по ландшафтному дизайну. Включение в образовательную среду технологии виртуальной реальности повышает уровень информационно-образовательной среды, способствуя творческому освоению пространства для дизайнерского проектирования.

Ключевые слова: 3D технологии, трехмерное моделирование, дополненная реальность, виртуальная реальность, ландшафтный дизайн, проектирование.

\section{VIRTUAL REALITY TECHNOLOGY IN LANDSCAPE DESIGN TRAINING}

\section{Li Mengxin}

Avetisyan Javad Davidovich Katkhanova Yulia Fedorovna

Abstract: The authors of the article show the capabilities of virtual reality technology, which has transferred education, business and other human activities into three-dimensional space. Virtual reality provides complete immersion in the 
computer environment surrounding the user and responds to his actions in a natural way. Today, this technology has begun to be used in the process of training landscape design specialists, providing experience in studying landscape objects by comparing various plans with each other, determining the most acceptable options for the implementation of landscape design projects. The inclusion of virtual reality technology in the educational environment increases the level of the information and educational environment, contributing to the creative development of space for design.

Key words: 3D technologies, three-dimensional modeling, augmented reality, virtual reality, landscape design, design.

\section{Взаимодействие с цифровым миром.}

Главная особенность современной цивилизации - активное развитие информационно-коммуникационных технологий. С их развитием человек перешел к другому уровню взаимодействия с цифровым миром, который занимает особое место в экономике, политике, производстве, культуре, образовании. Большое количество отраслей науки и производства сейчас используют персональные компьютеры для ускорения решения различных насущных и технологических задач. В том числе протерпели большие изменения в сфере городского планирования, в архитектурном дизайне, городском и ландшафтном дизайне. В системе образования также стали использоваться различные 3D технологии, в том числе дополненной и виртуальной реальности.

\section{D объекты и их возможности.}

Технологии визуализации в любой сфере деятельности является незаменимым средством демонстрации в процессе проектирования разного рода сложных объектов. К одной из таких технологий относится 3D, которое возникло вместе с развитием киноиндустрии, экономического и общественного прогресса и компьютеризации образовательной среды [1]. Сегодня 3D изображения являются активно используются в рекламе, в дизайнерской деятельности, проектных работах различного назначения. Сферой применения 3D могут быть корпоративные презентации, ролики, мультимедийные презентации. Именно 3D графика перенесла процесс обучения, бизнес и другие виды деятельности в трехмерное пространство. С помощью 3D мы можем увидеть объекты, которые не существуют в данный момент. Или существуют, но их нельзя увидеть вживую. Современная 3D графика сегодня используется для проектирования не только окружающей предметной среды, но и целых миров. 


\section{Возможности виртуальной реальности.}

Виртуальная реальность используется в городском планировании. Она активно включается в картографию, управление ресурсами, экологический мониторинг, в туристический бизнес, в землеустроительные и градостроительные системы, в городское планирование, управление транспортом и др. В наше время создание трехмерных объектов и построение виртуальной трехмерной сцены эффективно, наглядно и свежо в демонстрации участка зоопарка, сквера, детской площадки, садового участка и других объектов и строений. Главное - мы понимаем пространство или мир, который создается в очках виртуальной реальности, доступ к которому можно получить с помощью специальных устройств. Так, видео 360 идеально подходят для корпоративного сектора, когда нужно рассказать о компании, людях, офисе или показать производство, склады, магазин - так в реальной жизни возникает эффект присутствия. Если добавить аудио эффекты и анимацию, то можно усилить восприятие происходящего [2]. Отметим, что видео 360 существенно отличается от 3D-экскурсий. Когда мы говорим про экскурсию в $3 \mathrm{D}$, то мы подразумеваем статичный контент, который мы наблюдаем из одной точки и можем перемещаться в другую при помощи точек перехода. Видео 360 позволяет создавать эффект погружения в компьютерную среду, реагируя на пользователя и его действия. Мы видим не статичную картинку, а реальное видео, когда передвигаться в пространстве мы можем при помощи джойстиков. Решения с виртуальной реальностью использовалось в формате видео 360 для конгрессно-выставочного комплекса Экспофорума, поднимающий вопросы развития как площадки, так и возможности её резидентов от промышленности, продажи недвижимости, дизайна интерьеров и др. Причем, видео 360 можно использовать для любых задач, например, для обозрения ландшафта, для показа ландшафта будущего и др. Такое видео информативно за счет присутствия в конкретном месте и новых возможностей изменения ландшафта в проекте. Особенно запоминается возможность добавлений эффектов не только в виртуальную, но и в дополненную и смешанную реальность.

\section{Важность виртуального моделирования.}

Если дополненная реальность (AR) «улучшает» наш реальный мир, и мы можем видеть на реальных объектах дополнительную информацию, целые предметы или инсталляции, то технология виртуальной реальности (VR) является важным средством виртуального моделирования. Отметим, что виртуальное моделирование - это совокупность технологий моделирования, компьютерной графики, мультимедийных, сетевых и других технологий, включая среду моделирования, восприятия и зондирования. С помощью 
3D-технологий, технологии мультисенсорного взаимодействия и других создается яркая и реалистичная виртуальная среда. Причем, пользователь может войти в виртуальное пространство и стать частью виртуальной среды, надев соответствующее оборудование. Таким образом, человек приобретает настоящие ощущения, как будто находится на месте происшествия. Интерактивная, иммерсионная и концептуальная технология виртуальной реальности, используемая в обучении ландшафтному дизайну, может восполнить недостаток личного опыта в традиционном онлайн-образовании, а также может помочь студентам лучше понять, что такое ландшафтный дизайн и технология его проектирования.

\section{Трехмерный дисплей для виртуальной реальности.}

Виртуальный ландшафт - это применение технологий виртуальной реальности в ландшафтном дизайне, которая широко используется в индустрии недвижимости, особенно в архитектурном дизайне, где 3D-дисплей стал обычным средством отображения. Например, строительство Бурдж-Халифа, самого высокого здания в мире. Его строительство началось в 2004 году, а в эксплуатацию было введено в 2010 году. На ранней стадии строительства план был преобразован в трехмерный виртуальный дисплей. Сверхбольшое пиксельное представление точно отображало детали здания и окружающей среды. Использование виртуальной реальности, цифровых выставок и цифровых фильмов может помочь проектным компаниям демонстрировать объекты в пространстве. С такой технической поддержкой применение технологии отображения трехмерного эффекта в обучении ландшафтному дизайну становится весьма популярной (рис. 1).

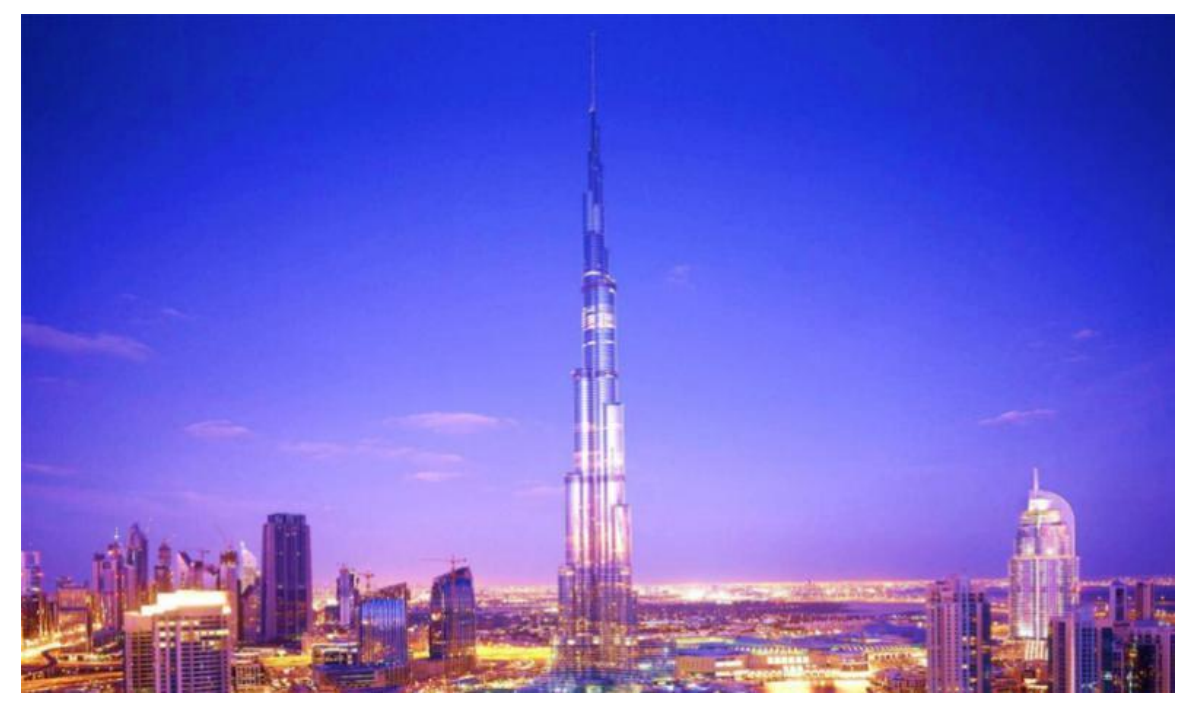

Рис. 1. Бурдж-Халифа 


\section{Преимущества 3D-технологий в обучении ландшафтному дизайну.}

Плоский ландшафтный дизайн вступает в противоречие с технологией трехмерной виртуальной реальностью. Отсюда постепенно рождается план ландшафтного дизайна с трехмерной визуализацией. Внедрение технологии виртуальной реальности в обучении ландшафтном дизайну означает использование сопутствующих технологий для выполнения трехмерного моделирования инженерных проектов, а также для получения различных проектных и строительных проектов моделирования в соответствии с планом ландшафтного проектирования [3]. При этом первоначальный дизайн плана является трехмерным. Различные строительные планы могут быть смоделированы на месте и сравнены в симуляциях для определения наиболее подходящего плана и процедуры ландшафтного дизайна, а также конкретных планов строительства и мер предосторожности в строительном проекте. В этом случае обучающиеся сталкиваются с путаницей, возникают вопросы в процессе обучения ландшафтному дизайну. Если учитель не может на них ответить, то они легко впадают в недоразумение, и их личностное развитие затормаживается. В связи с потребностью собственного развития учащимся необходим канал для получения большого количества информации о дизайне. В этом случае технология виртуальной реальности в основном может удовлетворить потребности учителя и учащихся в получении информации в связи с тем, что отображение в 3D-моделировании всегда реалистичны и интуитивно понятны. При этом «создается новая форма образовательной среды, характеризующейся, в первую очередь, «фотографической» памятью, расширением памяти визуализацией, усилением информации, а также синтезом знаний, культуры, образования и высоких технологий» [2, С. 57], которые могут повысить эффективность общения учителя и обучающегося и улучшить качество образования.

\section{Точность проектирования и эффективность расчетов.}

Ключевой технологией системы виртуальной реальности в выражении данных является технология трехмерных баз данных в реальном времени. Огромная база данных удобна для студентов. Она позволяет точно измерить количество инженерных работ и время строительства проекта, стоимость и расходы по проекту, а также повысить точность и эффективность бюджета проекта. База данных виртуальной реальности обеспечивает реальную систему вспомогательными данными, такими как инженерные материалы и образцы материалов, предоставляя исчерпывающую информацию в виде изображений 
объектов для последующего моделирования. Предлагаются и планы дренажной и ливневой систем, схемы прокладки труб, расстановка колодцев, приемников дождя, а также данные высотных отметок пролегания дрен, врезок, выпусков из колодцев и др. Самое главное - можно подойти к создаваемому участку с любой стороны, «сажая» растения, подбирая плитку для дорожек и т.д. Учащиеся также могут исследовать аналогичные варианты проектов и формировать навыки проектирования в любое время с помощью Базы данных, получая углубленное понимание эффектов и материалов ландшафтного дизайна [4]. На основе технологии виртуальной реальности студенты могут определить и стоимость проекта, подобрав подходящие рабочие материалы. Технология виртуальной реальности предоставляет студентам базовую основу, хорошо сочетая виртуальную реальность с реальностью, формируя практические и деловые способности студентов (рис. 2).

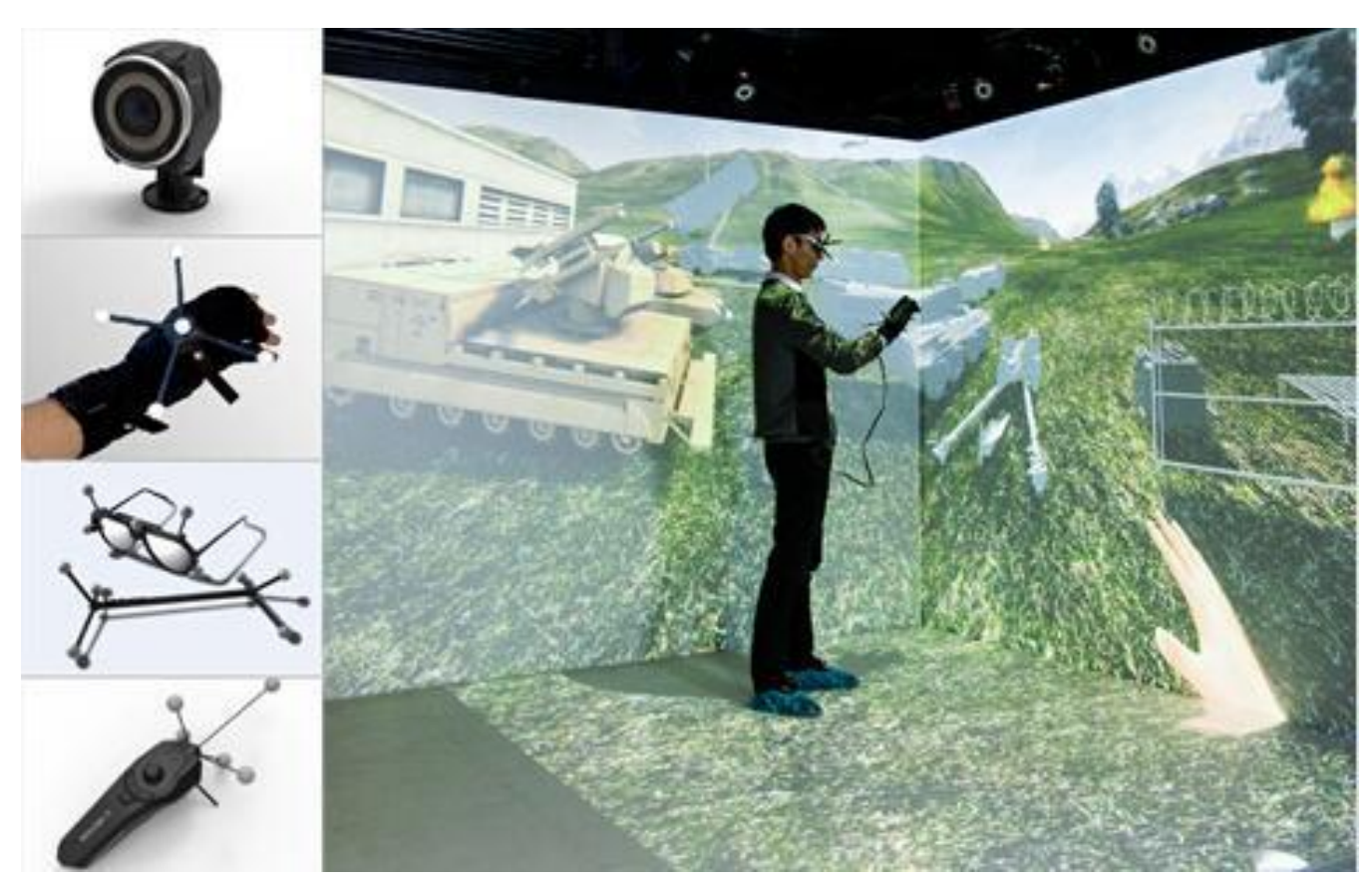

Рис 2. Оборудование, необходимое для технологии виртуальной реальности

\section{Общение между учителем и учащимися.}

Технология виртуальной реальности создала широкую платформу для визуального общения учителя с обучающимися [4]. Это стало чрезвычайно удобно благодаря существованию такой платформы. Передача специальных технических терминов, которые изначально были трудными для понимания, стала понятной благодаря визуальным возможностям технологии виртуальной реальности. В процессе проектирования, когда учащиеся не уверены в своих 
знаниях, они могут в любое время проконсультироваться с учителем, обменяться своими мыслями в процессе проектирования [5]. Учитель также может выдвинуть конструктивные предложения по улучшению 3D-модели. B итоге - для общения между учителями и студентам нет препятствий.

Только тогда, когда технология виртуальной реальности проникнет во все информационные системы, изменится режим взаимодействия человека с компьютером в традиционных информационных системах и сделают его системой, ориентированной на пользователя. Она может по-настоящему достичь значимого результата. Однако по-прежнему существуют некоторые технические трудности в связи с применением технологий виртуальной реальности и информационных систем. Поэтому сегодняшнее построение ландшафтного дизайна — это, в основном, ручное рисование. Отсюда необходимо нанимать отраслевую элиту с высокими зарплатами для профессионального проектирования курсов. Стоимость разработки программ и создания моделей, естественно, ошеломляет, но это неизбежные инвестиции.

\section{Аппаратная поддержка технологии.}

Bсе виды внешнего оборудования - незаменимые опоры для профессионального применения 3D-технологий в ландшафтном дизайне. Например, стереодисплеи, стереопроекторы и высокоточные перчатки для обработки данных, шлемы - все это стоит дорого. Кроме этого, чтобы завершить отображение сложной трехмерной модели, необходимо высокопроизводительное графическое программное обеспечение. Если университеты предоставят полный набор аппаратной поддержки технологии виртуальной реальности, первоначальные инвестиции должны быть больше, чем результат. Заметим, что продвижение новых технологий образовательного процесса всегда требует больших вложений. Поэтому технология виртуальной реальности по-прежнему остается в учебных заведениях передовой технологией в преподавании [5]. От преподавателей в данном случае требуется более высокий уровень профессионализма и компьютерных навыков. Однако, согласно теоретическому анализу их способностей в различных университетах было показано, что они могут хорошо управлять компьютерами, но пока мало что знают о технологиях виртуальной реальности.

Итак, обогащение содержания обучения ландшафтному дизайну технологией виртуальной реальности делает образовательный процесс более результативным. Учащиеся становятся более мотивированными и увлеченными процессом учения. Значительно повышается эффективность усвоения учебного 
материала за счет визуализации учебного процесса, используя технологию виртуальной реальности.

\section{Список литературы}

1. Юань Цзюнь. Исследование применения технологий виртуальной реальности при преподавании на курсах ландшафтного дизайна. Дом драмы, 2016.

2. Катханова Ю.Ф. Технология дополненной реальности в образовании [Текст] / Ю.Ф. Катханова, К.И. Бестыбаева // Педагогическое мастерство и педагогические технологии: материалы VIII Междунар. науч.-практ. конф. (Чебоксары, 17 июля 2016 г.) /редкол.: О.Н. Широков [и др.]. — Чебоксары: ЦНС «Интерактив плюс», 2016. - № 2 (8). — С. 289-291.

3. Ян Пин. Анализ применения технологий виртуальной реальности в обучении ландшафтному дизайну сада. Городская география, 2016 г.

4. Катханова Ю.Ф., Корзинова Е.И., Игнатьев С.Е. Визуализация учебной информации как педагогическая проблема. Вестник Адыгейского государственного университета. Серия «Педагогика и психология». - Майкоп: Изд-во АГУ. - Вып. 4 (228) - 2018. С. 51-60.

5. Ла Гоцин. Исследования по применению технологий виртуальной реальности в образовании. Журнал Института образования Сучжоу, 2015 г.

(С Ли Мэнсинь, Д.Д. Аветисян, Ю.Ф. Катханова, 2021 